\title{
Perdas dentárias e expectativas da reabilitação protética: um estudo qualitativo
}

\section{Dental losses and expectations of protetic rehabilitation: a qualitative study}

Gustavo Sales de Oliveira1 ${ }^{1}$ Vinicius Lopes Marinho²

\section{RESUMO}

Estudos realizados em populações idosas brasileiras na qual revelam um quadro de saúde bucal precária, destacando-se a grande quantidade de indivíduos desdentados totais e a ausência de programas preventivos de saúde bucal voltado para essa parcela da população. Diante do exposto realizou-se uma pesquisa descritiva com abordagem qualitativa com o propósito de investigar objetivo investigar a percepção das perdas dentárias e expectativas em relação à reabilitação protética em usuários da Clínica Escola de Odontologia de uma Universidade da região Sul do Tocantins. Os dados foram coletados por meio de entrevistas semiestruturadas e submetidos à análise de conteúdo. Participaram do estudo 9 indivíduos, sendo três do sexo masculino e seis do sexo feminino. A faixa etária variou entre 41 anos e mais que 60 anos. A grande maioria $(90 \%)$ possuíam perdas em ambas as arcadas dentárias e já faziam o uso de prótese. Concluiu-se que a perda dentária exerce grande influência no estado emocional do paciente, repercutindo negativamente no bem-estar físico e psicológico, pois debilita a estética e algumas atividades cotidianas. Porém após serem investigados prováveis problemas de saúde nos indivíduos desdentados, raramente foi feito menção à questão da perda dentária como um problema de saúde bucal, pois o entendimento é de que a remoção dos dentes pode ser a solução para esses problemas.

Palavras-chave: Edentulismo. Idosos. Aspectos Emocionais.

\section{ABSTRACT}

Studies carried out in Brazilian elderly populations show a precarious oral health situation, highlighting the large number of edentulous individuals and the absence of preventive oral health programs aimed at this part of the population. In view of the above, a descriptive research with a qualitative approach was carried out with the purpose of investigating the objective to investigate the perception of dental losses and expectations regarding prosthetic rehabilitation in users of the Clinical School of Dentistry of a University of the South of Tocantins. Data were collected through semistructured interviews and submitted to content analysis. Nineteen individuals participated, of which three were male and six were female. The age range ranged from 41 years to more than 60 years. The vast majority $(90 \%)$ had losses in both dental arches and were already using a prosthesis. It was concluded that tooth loss exerts a great influence on the patient's emotional state, negatively impacting on physical and psychological well-being, since it weakens esthetics and some daily activities. However, after investigating probable health problems in edentulous individuals, mention was rarely made of the issue of tooth loss as an oral health problem, as the understanding is that tooth removal may be the solution to these problems

Key words: Edentulism. Elderly. Emotional Aspects.
Odontólogo pela Universidade de Gurupi/UnirG.

2Psicólogo, Professor Adjunto da Universidade de Gurupi/UnirG, Doutorando em Ensino pela Universidade do Vale do Taquari/Univates, Mestre em Ciências da Saúde pela Universidade Federal do Tocantins/UFT

Endereço

correspondência:

para

Vinicius Lopes Marinho

Universidade de Gurupi/UnirG,

Av. Rio de Janeiro no 1585, Centro

77403-090, Gurupi - TO,

Telefone: (63) 3612-7600. 


\section{INTRODUÇÁO}

Durante muitos anos, a condição de saúde bucal da população brasileira, incluindo adultos e idosos carregam a herança de um modelo assistencial centrado em práticas curativas e mutiladoras, o que resulta em um cenário de ausência de dentes e acúmulo de necessidades de grande demanda por serviços protéticos (MALLMANN et al., 2012).

Olchik, et al. (2013) apontam estudos realizados em populações idosas brasileiras na qual revelam um quadro de saúde bucal precária, destacando-se a grande quantidade de indivíduos desdentados totais e a ausência de programas preventivos de saúde bucal voltado para essa parcela da população.

O edentulismo é a perda total ou parcial dos dentes permanentes e ocorre como conseqüência de eventos mutilatórios que se sucedem durante toda a vida. Decorre, na maioria das vezes, de uma prática voltada para extrações dentárias subsequentes a agravos bucais como cárie dental e problemas periodontais não sendo, portanto, decorrente do envelhecimento (VOLPATO et al. 2013).

A ausência dos dentes interfere diretamente na estética, fonação, e principalmente na capacidade mastigatória, o que leva as pessoas a modificarem seus hábitos alimentares por alimentos mais macios, de fácil mastigação e, muitas vezes, de valor nutritivo crítico. Além disso, os aspectos psicológicos e sociais são evidentes através do descontentamento em relação à atividades sociais, como refeições, com a família ou amigos, forçando muitas vezes, a permanecerem em casa, isolados do convívio social, afetando diretamente a sua qualidade de vida (SILVA et al., 2010).

Uma das principais justificativas para a extração total dos dentes, é que ela representa uma solução definitiva para aspectos ligados à dor, juntamente, com a dificuldade no acesso aos serviços de atenção à saúde bucal, a falta de recursos financeiros para o tratamento necessário e a falta de informação sobre os cuidados com a boca, tem sido apontado como as principais causas da perda dentaria (SILVA et al., 2010).

Neste contexto o impacto dessa condição tem grande repercussão sobre a qualidade de vida das pessoas, pois afeta tanto a estética quanto o psicológico do indivíduo, reduzindo a autoestima e a integração social.

É sabido que a ausência de dentes influencia diretamente o cotidiano das pessoas, afetando a sua qualidade de vida. Assim, mais que restabelecer a função mastigatória, 
ao procurar o tratamento reabilitador, os pacientes buscam reconstituir sua imagem pessoal, social e sua qualidade de vida (SILVA, MAGALHÃES E FERREIRA 2010).

Diante do exposto, questionou-se quais os sentimentos de usuários da Clínica Escola de Odontologia do Centro Universitário Unirg com perda dentária total e prestes a incorporar próteses, no que diz respeito às dificuldades, às suas impressões em relação às implicações dessa perda em suas vidas e quais suas expectativas quanto a reabilitação protética?

Partiu-se do pressuposto de que as perdas dos dentes interferem na vida diária dos indivíduos, gera uma desestabilização do sistema estomatognático, restringindo duas funções importantes para a sobrevivência: a fonação e a mastigação, dificultando e limitando o consumo de diversos alimentos. Além disso, o impacto dessa condição gera grande repercussão na qualidade de vida do indivíduo, afetando tanto a estética quanto o psicológico do indivíduo, reduzindo a autoestima e a integração social.

Desta maneira, o presente estudo teve como objetivo investigar a percepção das perdas dentárias e expectativas em relação à reabilitação protética em usuários de uma Clínica Escola de Odontologia de uma Universidade do Sul do Tocantins.

\section{MATERIAIS E METODOS}

Tratou-se de um estudo descritivo com abordagem qualitativa realizada com usuários da Clínica Escola de Odontologia de uma Universidade do Sul do Tocantins. Participaram da pesquisa nove (09) usuários. Os critérios de inclusão para a participação no estudo foram: ser edêntulo total, estiver iniciado tratamento em 2018/1 e aceitar a participar da pesquisa. Foram excluídos do estudo usuários que fossem edêntulos parciais e que já estivessem iniciado o tratamento antes do período mencionado (2018/1).

O estudo seguiu o que prevê a resolução 466/2012 do Conselho Nacional de Saúde sendo submetida a um Comitê de Ética em Pesquisa com Seres Humanos sob CAAE: 63946316.3.0000.5518 e aprovada conforme parecer $n^{\circ}: 1.915 .986$. A coleta de dados foi realizada por meio da técnica de entrevista semiestruturada que foi realizada nas dependências da Clínica Escola de Odontologia da Universidade de Gurupi. As entrevistas foram gravadas em aparelho MP4, e a transcrição ocorreu no mesmo dia da entrevista, evitando-se a perda dos detalhes das falas dos entrevistados. A entrevista permitiu captar gestos, reações faciais, sentimentos manifestos, sendo estes fundamentais para análise do material coletado. A duração foi de 45 minutos a 1 hora e 30 minutos. Para tratamento dos dados utilizou da análise conteúdo de Bardin, através da análise categorial temática. 
Preservou-se o anonimato dos usuários, a estes foram atribuídos nomes fictícios. Ao final da análise categorial temática emergiu as seguintes categorias: 1-Causas das Perdas Dentárias, 2-Percepção, Consequências das Perdas Dentárias, 3-Expectativas em Relação à Reabilitação Protética e 4-Significado dos dentes.

\section{RESULTADOS}

Participaram do estudo 09 usuários da clínica escola de Odontologia. Inicialmente foi realizada uma caracterização dos participantes levando em consideração as seguintes variáveis: Gênero, Faixa Etária, Nível de Escolaridade, renda, caracterização da perda dentária (arcada superior, inferior ou ambas) e utilização de prótese.

Tabela 1 - Caracterização dos participantes da pesquisa.

\begin{tabular}{lcc}
\hline VARIÁVEIS & N. & $\%$ \\
\hline GÉNERO & 03 & \\
Masculino & 06 & 60 \\
Feminino & & 60 \\
FAIXA ETÁRIA & - & - \\
Menor que 30 anos & - & - \\
31 a 40 anos & 01 & 10 \\
41 a 50 anos & 05 & 60 \\
51 a 60 anos & 03 & 30 \\
Acima de 60 anos & 06 & 70 \\
ESCOLARIDADE & 02 & 20 \\
Ensino fundamental incompleto & - & - \\
Ensino fundamental completo & - & - \\
Ensino médio incompleto & 01 & 10 \\
Ensino médio completo & - & - \\
Ensino Superior Incompleto & & 100 \\
Ensino Superior Completo & 09 & - \\
RENDA & - & - \\
Um salário Minimo & - & 10 \\
Dois salários Mínimos & & - \\
Acima de dois salários Mínimos & 01 & 90 \\
PERDA NA ARCADA DENTÁRIA & - & 90 \\
Superior & 08 & 10 \\
Inferior & & \\
Ambas & & \\
UTILIZAÇÃO DE PRÓTESE & & \\
Sim & &
\end{tabular}

A amostra participante da pesquisa foi caracterizada sendo que $60 \%$ era do sexo feminino, $90 \%$ possuíam idade superior entre 50 a acima de 60 anos. Em relação ao nível 
de escolaridade $90 \%$ possuía o nível fundamental, seja ele completo ou não. Em relação a renda verificou-se uma população de baixa renda que vive, em sua grande maioria, de sua aposentadoria. A maioria dos participantes já utiliza prótese, sendo a grande parte deles em ambas as arcadas.

\section{Causas das Perdas Dentárias}

Para alguns indivíduos, a doença bucal era concebida como um processo natural, sem causa definida, e por isso atribuía a perda dos dentes a uma evolução natural. No presente estudo constatou-se que as causas das perdas dentarias estavam relacionadas a falta de conhecimento dos meios para a manutenção dos dentes, a dificuldade de acesso aos serviços de atenção à saúde bucal, a falta de recursos financeiros para o tratamento necessário conforme evidenciado nos relatos abaixo:

[...] "Não cuidava, eu morava no interior, e lá não tinha tratamento, eu morava na roça, e lá a gente não tinha cuidados, só ia estragando, apodrecendo." (José)

[...] "Eu morei quase minha vida inteira na roça, e la não tinha tratamento nenhum, quando doía os dentes, a gente colocava leite de cansanção para alivar a dor, quando isso não resolvia, nós "rancava" o dente no povoado vizinho. Perdi todos os meus dentes há 15 anos atrás". (Raimundo)

Percebeu-se que a maioria dos entrevistados havia perdidos os dentes há mais de 10 anos e um dos principais motivos foi o modelo de atenção a saúde bucal inexistente no passado conforme explicitado nos relatos dos participantes Ivanir e Pedro:

[...] "então agente ia para arrancar, naquela época não tinha tratamento de dente." (Ivanir).

[...]"não tinha nenhum tratamento de dente, então quando começava as dores eu corria na cidade vizinha, e pedia para extrair. (Pedro)

Outro aspecto evidenciado nos relatos de grande parte dos participantes é que a perda dos dentes era a única forma de encontrar alívio para a dor causada pela condição bucal. 
"eu pensei assim vou rancar logo tudo pra dá um alivio pra mim, porque brocava um dente e pouco tempo depois brocava os outros". (João)

\section{Percepção e Consequências das Perdas Dentárias}

Segundo Silva, Magalhães e Ferreira (2010) perder os dentes é considerado, pela sociedade em geral e até por profissionais da odontologia, como um acontecimento normal, uma conseqüência do passar dos anos, no entanto cada indivíduo passa por esse processo dando significado a tais perdas, conforme os relatos abaixo:

[...] "Depois que perdi todos os dentes, que eu pude ver que eles são muito importantes, tenho varias dificuldades, depois que perdi eles". ( Pedro)

[...] "É muito ruim, sinto muita falta dos meus dentes verdadeiros, com eles eu comia qualquer coisa, tinha uma alimentação variada, hoje só me alimento de comida cozida, bem cozida na panela de pressão, para conseguir engolir". ( Claudia)

[...] "É horrível, em todos os aspectos, na estética, na beleza da pessoa, para se alimentar, poder comer qualquer coisa, conversar com as pessoas, sem medo, sem falar da auto estima pessoal". (Socorro)

Em se tratando das consequências da perda dos dentes, verificou-se prejuízos funcionais a ela associados, o constrangimento implícito à falta dos dentes e o sentimento de incompletude experimentado nesse caso.

[...] "Minha grande dificuldade é na hora da comida, tem certos alimentos que tenho que bater no liquidificador ou amassar, para conseguir engolir". (Raimundo)

[...] isolamento social, dificuldade e medo em me relacionar com as pessoas, não conseguir arrumar um namoro. "Conviver no meio da sociedade, por que os dentes é tudo, parece que as pessoas não chegam nem perto de você, parece que tem nojo". ( José)

[...] Minha autoestima que sempre anda baixa, por ter medo de conversar com as pessoas, das mesmas repararem na minha boca, não poder sorrir a vontade, são muitas as consequências de uma vida sem dentes. (Socorro)

\section{Expectativas em Relação à Reabilitação Protética}

No que diz respeito à expectativa dos pacientes em face da reposição protética dos dentes, foi possível observar que as preocupações. 
[...] "Irá melhorar muita coisa, vou poder sorrir espontaneamente, poder me alimentar melhor, e com isso ter uma auto estima elevada novamente, é tudo que eu mais quero". ( Socorro)

[...]"Vou ter mais confiança em poder fazer coisas simples da vida, como me alimentar na frente dos outros e poder sorrir a vontade. Quero uns dentes mais bonitos também, dentes mais brancos. "( Raimundo)

[...]"Vai mudar a forma deu conversar, por que ela não vai ficar caindo, vou poder me alimentar direito, comer varias coisas, e sem falar que a feição muda, agente fica com o rosto mais bonito, não fica com boca murcha". ( José)

\section{Significado dos dentes}

A presente categoria tem como objetivo apresentar a atual percepção dos participantes sobre os dentes e sua contribuição para o cotidiano. Verificou-se no relato dos participantes que a importância para os dentes só veio após a vivência das consequências de não tê-los.

[...] " Depois que agente perde, que agente vê, a importância dos dentes naturais, o tanto que nos faz falta, em varias situações das nossas vidas." ( Pedro)

[...] "Hoje vejo o tanto que os dentes são importantes, tanta falta que eles nos faz, em varias coisas da vida, principalmente na mastigação, poder comer qualquer coisa, não tem nada melhor. Na aparência da gente, sem os dentes nos ficamos feia, a boca murcha, fica parecendo ser ate mais velha". ( Raimundo)

Segundo Souza e Silva (2010) com a ausência dos dentes a função do sorriso não se completa devidamente, sendo que eles relacionam-se, mais frequentemente, à juventude, beleza, produtividade e possibilidade de realização. Assim sendo, a sua reposição visa a um retorno à aparência anterior e, consequentemente, os dentes são considerados aspectos importantes nas relações empregatícias, sociais, culturais, além de influenciar na autoestima das pessoas. Foi possível perceber também que grande parte dos participantes reconhece a importância da prótese, porem acredita que nunca será igual aos dentes. 
[...] "a prótese nunca vai ser igual os dentes verdadeiros, mais podemos ter uma vida socialmente normal e nos ajuda na hora da alimentação". ( Raimundo)

[...] "A prótese vai me ajudar a realizar essas tarefas, mais nunca vao ser iguais os dentes de verdade". (Claudia)

A prótese tem um significado particular na vida de cada participante, contribuindo em diversos aspectos em sua vida. Verificou-se que alguns participantes não se permitem ficar sem utilizá-la, conforme relatos a seguir:

[...] " Não fico sem ela em nenhum momento, me sinto muito ruim sem ela, a sensação da boca vazia é muito ruim". (Joana)

[...]"Eu não tiro, eu durmo com ela, fico o tempo todo com ela. Me sinto muito ruim quando estou sem ela, a boca fica vazia, é uma sensação desagradável". (José)

[...]"Não tiro a prótese em nenhum momento, me sinto muito ruim sem ela, a sensação de boca murcha, boca vazia".( Socorro)

Tal situação é semelhante ao constatado no estudo de Ciarântola (2010), que verificou que a reação mais comum relatada quando o paciente encontra-se sem a prótese é evitar que as outras pessoas o vejam, ou seja, as pessoas disseram evitar olhar-se no espelho sem a dentadura, seja pelo fato de o lábio ficar murcho, por se acharem mais feios ou por sentirem-se estranhos.

Nesta direção, os estudos feitos por Botelho et al.(2013) mostram que uma pessoa que perde um órgão sofre modificações bruscas em sua vida, afetando diretamente seu comportamento e a maneira de agir. Segundo Ferreira et al. (2016), com a perda dos dentes, o equilíbrio bucal é afetado, o que acaba por impor às pessoas mudanças fisiológicas, biológicas, emocionais e sociais.

[...] "Era tudo ne, me arrependi por não ter tratado, os dentes verdadeiros são tudo na nossa vida, pra gente viver com a auto estima e confiança, sem medo de comer ou de sorrir, agora não tem jeito mais, agora é me conformar com a prótese para ter uma vida saudável. ( José)

[...] "Se eu soubesse o valor que os dentes naturais tem em nossa vida, teria cuidado deles, procurado um tratamento para arrumar ou restaurar os dentes. ( Joana) 
Este sentimento também foi evidenciado no estudo de Dantas (2007). Seu estudo mostrou que as pessoas expressam em seus discursos um sentimento de falta e arrependimento por terem perdido os dentes, embora haja um pensamento por parte daqueles que constituem os serviços públicos odontológicos em relação à desvalorização da dentição natural pelos usuários.

\section{DISCUSSÃO}

Para Dantas (2007) dados epidemiológicos brasileiros têm mostrado expressivo incremento das perdas dentais com o avanço da idade.

Vargas (2005) acredita que grande parte dessas pessoas sejam obrigadas a se mutilar por não possuírem condições econômicas para pagamento do tratamento necessário e por falta de acesso a um serviço público que tenha uma resolutividade melhor e não ofereça somente extrações, como tratamento.

Segundo Silva, Magalhães e Ferreira (2010) o edentulismo no Brasil, assim como em outros países menos desenvolvidos, relaciona-se com fatores econômicos. Indivíduos com menor escolaridade, pobres e moradores em zonas rurais têm maior probabilidade de se tornar edêntulos.

Em relação ao achado desta pesquisa, onde grande parte dos entrevistados perderam os dentes a mais de dez anos e um dos principais motivos foi o modelo de atenção a saúde bucal inexistente no passado A justificativa para a situação segundo Ciarântola (2010) é que no Brasil, a extração dentária em massa começa a partir dos 30 anos, como solução mais prática e econômica para os problemas de saúde bucal, sabe-se que as condições sociais dos indivíduos bem com o a prática odontológica hegemônica, que tem nas extrações dentárias a solução para o alívio da dor em populações de baixo nível socioeconômico, exercem um importante papel na questão da perda dentária.

Nesta direção Soares et. al (2015) ressaltam que a odontologia através dos séculos, estava primariamente concentrada na remoção das unidades dentárias, e o sucesso do tratamento era associado a eliminação da dor. No estudo evidenciou-se que a extração dos dentes foi a solução mais rápida e acessível da remoção da dor.

As consequências evidenciadas nesse estudo se assemelham com os estudos de Soares et.al, (2015); Ciarântola (2010), segundo eles funções normais como mastigação, fala e sorriso podem ser prejudicas pela perda natural dos dentes. Já Sá, Hübner e Reis (2005) consideram que funções sociais como comunicação e estética podem ser mais 
importante para o indivíduo do que mastigação e mordida, e devem ser os principais determinantes dos sentimentos referentes às perdas dentárias.

Nesta mesma direção, Vargas e Paixão (2015) constataram em seu estudo que os problemas na vida diária relacionados com a perda dentária foram de ordem funcional como comer, mastigar ou falar; e social, como mudanças no comportamento e insatisfação com a aparência.

Segundo Souza e Silva (2010), a expectativa de recomposição da cavidade bucal gera grande ansiedade, principalmente em relação à estabilidade e adaptação das próteses totais removíveis. Achados na literatura destacaram a importância do caráter social da prótese, reintegrando o usuário ao convívio social, portanto, a reabilitação protética deve proporcionar não apenas a função dentária e/ou bucal, mas também a reintegração desse indivíduo na comunidade a que pertence. Pesquisas ainda reiteram que a observação de aspectos estéticos relacionados com a face torna o trabalho mais aceitável do ponto de vista estético.

No que diz respeito à ausência dos dentes Silva e Magalhães (2007) afirmam que a mesma pode gerar sentimentos de insegurança, impotência e vazio. Uma boca com dentes é uma maneira de como o sujeito se apresenta de acordo com as normas da sociedade, portanto, sua falta é uma ameaça à identidade individual, social e familiar. Ao serem vivenciadas as limitações ocorridas da condição de desdentado e usuário de prótese, vem à tona o arrependimento pela perda e, ao mesmo tempo, o desejo de ter de volta os dentes naturais.

\section{CONSIDERAÇOES FINAIS}

Concluiu-se que a perda dentária exerce grande influência no estado emocional do paciente, repercutindo negativamente no bem-estar físico e psicológico, pois debilita a estética e algumas atividades cotidianas. Como consequências da perda dos dentes, apontaram-se os prejuízos funcionais a ela associados, o conformismo à situação consequente, o constrangimento implícito à falta dos dentes e o sentimento de incompletude experimentado nesse caso.

Porém após serem investigados prováveis problemas de saúde entre indivíduos desdentados, raramente se faz menção à questão da perda dentária como problema de saúde bucal, pois o entendimento de que a remoção dos dentes pode ser a solução para os problemas de saúde bucal é resultado, também, da articulação de conceitos culturais e 
médicos, que determinam o agir frente a diferentes ocorrências desses problemas, pois mesmo aqueles que conseguem atendimento odontológico são estimulados a extração dentaria.

\section{REFERENCIAS}

CIARÂNTOLA, M. Aspectos psicossociais relacionados à perda dental e uso de próteses em adultos. Monografia (Graduação em Odontologia), Universidade Estadual de Campinas, Faculdade de Odontologia de Piracicaba, Piracicaba, 2010.

DANTAS, J. A. A produção das perdas dentárias: narrativas de usuários do SUS. Dissertação (Mestrado em Ciências da Saúde). Departamento de Odontologia, Universidade Federal do Rio Grande do Norte, Natal, 2007.

FERREIRA, A. A. A. et al. A dor e a perda dentária: representações sociais do cuidado à saúde bucal. Ciência \& Saúde Coletiva, v. 11 no1. 2016. Disponível em: http://www.scielo.br/pdf/\%0D/csc/v11n1/29466.pdf. Acesso em Março de 2018.

MALlMANN, F. H.; TOASSI, R. F. C.; ABEGG, C. Perfil epidemiológico do uso e necessidade de prótese dentária em indivíduos de 50-74 anos de idade, residentes em três 'Distritos Sanitários' de Porto Alegre, Estado do Rio Grande do Sul, Brasil, em 2008. Epidemiologia e Serviços de Saúde, Brasília, v. 21, n. 1, p. 79-88, 2012.

OLCHIK, M.R. et al. O impacto do uso de prótese dentária na qualidade de vida de adultos e idosos. Rev Kairós Gerontologia, v. 16, n. 5, p. 107-121, Set., 2013.

SÁ, C. N.; HÜBNER, S.; REIS, S. R. A. Efeitos emocionais da perda dos dentes em adultos. Revista Faculdade de Odontologia, v. 46, n. 2, p. 9-14, 2005.

SILVA, M. E. S.; MAGALHÃES, C. S.; FERREIRA, E. F. Perda dentária e expectativa da reposição protética: estudo qualitativo. Ciência \& Saúde Coletiva, v.15, n.3, p. 813-820, 2010.

SILVA, D. R. V.; MAGALHÃES, R. F. Significados das perdas dentárias e da reabilitação oral, com auxílio da prótese parcial removível, para os pacientes atendidos nas clínicas do Curso de Odontologia Univali. Monografia (Graduação em Odontologia), Universidade do Vale de Itajaí. Itajaí, 2007.

SOARES, S. L. B. et al. Avaliação dos usuários de prótese total, abordando aspectos funcionais, sociais e psicológicos. Revista Saúde e Ciência, v. 15, n. 3, p. 813-820, 2015.

VARGAS, A. M. D.; PAIXÃO, H. H.Perda dentária e seu significado na qualidade de vida de adultos usuários de serviço público de saúde bucal do Centro de Saúde Boa Vista, em Belo Horizonte. Ciência \& Saúde Coletiva, v. 10, n.4, p.1015-1024, 2015.

VOLPATO, C.A.M. et al. Próteses odontológicas: uma visão contemporânea fundamentos e procedimentos. 1aㅡ ed. São Paulo: Santos, 2013. 482p. 